\title{
THE ASSESSMENT AND RANKING OF FAILURES IN THE INFORMATION TECHNOLOGY INDUSTRY BASED ON FMEA AND MCDM
}

\author{
Marin Peko', Nikola Komatina*2, Nikola Banduka, ${ }^{1,2}$ and Marina Crnjac ${ }^{2}$ \\ ${ }^{1}$ Faculty of Electrical Engineering, Mechanical Engineering and Naval Architecture, University of \\ Split, Split, The Republic of Croatia \\ ${ }^{2}$ Faculty of Engineering, University of Kragujevac, Kragujevac, The Republic of Serbia
}

In the course of global trends, the development and application of information technologies have emerged as a valuable source of the economy at both the micro and the macro levels. According to the results of the best practice, the application of a piece of software with failures is known to possibly to serious consequences. The analysis and elimination of potential failures in commercial software is the problem that represents one of engineers' most important tasks. In this paper, a new integrated model for the evaluation and ranking of software failures is proposed. The cost aspect is integrated into the traditional severity index. The assessment of the severity indices, as well as a possibility of detection, is based on the Failure Mode and Effects Analysis - FMEA framework. The weights of the overall severity index, the occurrence of failures, and the possibilities of detection are calculated by applying the best-worst method. The determination of the rank of the identified failures is given by applying conventional Technique for Order of Preference by Similarity to Ideal Solution - TOPSIS. The priority of the activities that are undertaken in order to eliminate the identified failures corresponds to the obtained rank of the failures. The proposed model is illustrated by real-life data.

Keywords: software development, Failure Mode and Effects Analysis, Best-Worst method, Technique for Order of Preference by Similarity to Ideal Solution

\section{JEL Classification: C6, 12}

\section{INTRODUCTION}

The development of the information technology (IT) sector has significantly been changing the habits and

* Correspondence to: N. Komatina, Faculty of Engineering, University of Kragujevac, Sestre Janjic 6, 34000 Kragujevac, The Republic of Serbia; e-mail: nkomatina@kg.ac.rs needs of people. Nowadays, people are completely surrounded by information technologies, starting from smartphones, computers, smart TVs, via other new-generation home appliances, to their jobs, where work is unimaginable without information technologies. Today, the information technology sector is one of the main drivers of the development 
of the economy (Papaioannou \& Dimelis, 2007) because the products and services in this domain are very much required on the market. Many countries highlight the IT sector as one of the pillars of their economic development and invest in the education of the necessary staff (Dedrick, Kraemer \& Shih, 2013).

According to the lean concept of enterprise management and the results of good practice, it is known that if the final product, a piece of software in this particular case, has a failure in itself and reaches the customer it can bring about catastrophic consequences to the company, such consequences reflecting in a decrease in the profit, lesser market competitiveness, a loss of customers, etc. Therefore, the identification, analysis and elimination of a failure which may be found on a piece of software as a product is one of the most important tasks of both programmers and other engineers from within IT companies.

One of the most- used methods for failure analysis is the Failure Mode and Effects Analysis (FMEA), primarily in the automotive and airline industries. In the literature, there are papers treating the problem of the failure analysis of products and processes in the IT sector based on the FMEA framework (Signor, 2002; Silva, de Gusmão, Poleto, e Silva \& Costa, 2014). In conventional FMEA, the rank of failures is obtained according to the Risk Priority Number (RPN), which on its part is obtained as a product of all of the three considered criteria (severity, occurrence and detection). For the automotive industry, the values of these criteria and the rules for undertaking corrective actions are defined by the Automotive Industry Agency Group. The RPN range is (1-1000), whereas the values of the severity, occurrence and detection criteria have a range of (1-10). Corrective actions should be undertaken at any time, but especially when the RPN value exceeds 100, or one of the risk indices value exceeds 8 .

In the conventional FMEA method, the severities of consequences are assessed by observing the quality aspect. Many authors think it is necessary to consider the other aspects, primarily the cost aspect (Carmignani, 2009; Abdelgawad \& Fayek,
2010; Banduka, Tadić, Mačužić \& Crnjac, 2018). Cost estimation is made by using new calculation formulas as in G. Carmignani (2009). In the paper of M. Abdelgawad and A. R. Fayek (2010), the overall severity index is considered with respect to the three dimensions, namely: the cost, the time, and the quality/scope. N. Banduka et al (2018), define a new scale for cost assessment.

On the other hand, in the traditional FMEA method, all of the considered criteria are assumed to have equal relative importance. With respect to the results of the best practice, this assumption can be said not to be completely accurate. Hence, many authors suggest that the values and the rank of failures should be stated as a multi-criteria optimization (MCDM) problem (Song, Ming, Wu \& Zhu, 2014; Liu, You, Li \& $\mathrm{Su}, 2016)$. This problem can be solved by using one or a combination of several MCDM methods. The most used methods are the Analytic Hierarchy Process - AHP, the Technique for Order of Preference by Similarity to Ideal Solution - TOPSIS, etc.

The subject of this research is the evaluation of potential failures in software used for business process management problems.

The aim of the research study is to develop a new multi-criteria optimization model based on the FMEA framework for the estimation and ranking of failures in the IT sector.

According to the defined goal, the following hypotheses can be formulated:

H1 The evaluation and ranking of failures can be performed in an exact manner.

H2 By using the proposed method, the priority of the activities that need to be employed in order to eliminate a possibility of delivering the final product with a failure to the customer is determined in an exact manner.

Every solution obtained in an exact manner is known to be less burdened with decision-makers' subjective assessments and can be considered as more precise. On the other hand, the use of resources (human, 
time-related and financial) for failure elimination is significantly reduced, which further leads to a reduction in business expenses, i.e. to an increase in a profit.

The instrumentarium used in this paper can be described as follows: the severities-based and detection scenarios are defined according to the relevant literature and the expert opinion; the relative importance of severity, occurrence and detection is determined by applying the Best-Worst method (Rezaei, 2015); the ranking of failures can be performed by applying the Technique for Order of Preference by Similarity to Ideal Solution (TOPSIS) method (Hwang \& Yoon, 1981).

This paper is organized in five sections. In Section Two, a literature review of the relevant literature in the domain of the FMEA method and the MCDM method based on the FMEA framework for the assessment and selection of failures is given. Section Three presents the proposed model. In Section Four, the proposed model is tested by means of the literature data, whereas the conclusion is given in Section Five.

\section{LITERATURE REVIEW}

In the literature, there are a few papers addressing the problem of failure priority determination, which may occur in different products and in different sectors of information technology processes. Furthermore, a short analysis of the considered papers is shown, the main topic of these papers being the application of the FMEA analysis in the information technology domain.

M. C. Signor (2002) developed a model for risk priority determination, i.e. the Failure-Analysis Matrix (FAM), which is conceived as an alternative to the FMEA analysis in the information technology domain. The FAM matrix is based on the detection of the key failures, after which all potential solutions to the elimination of one single failure at least are necessary to find. Then, such alternative solutions are presented in rows, whereas the estimated costs of such solutions, the priority of a solution and a reduction in defects expressed in percentages are given in columns. The application of the created matrix reflects in the determination of the extent to which each such solution is effective when the elimination of each such failure is concerned. It depends on the extent to which the considered solution is good for the treatment of the considered failure, and such reduction in defects expressed in percentages is determined. It should be noted that the FAM matrix is significantly simpler and less extensive in comparison with the FMEA. That can be marked as the main advantage of FAM in comparison with the FMEA. When the FMEA is used, each potential failure is assumed to be taken into consideration, whereas in the FAM matrix, only a few failures with the biggest impact are considered. This is a significant disadvantage of the FAM matrix.

M. M. Silva et al (2014), employed the FMEA analysis and the fuzzy sets theory in order to identify and reduce the occurrence of failures in the information safety and data protection domain(s). By this approach, the five basic dimensions of information safety are analyzed, namely: access to information and systems, communication security, the infrastructure, security management, and secure information systems development. Each of these dimensions includes several (from 3 to 6) identified failure modes. Experts estimate the Occurrence, Severity and Detection of each such identified failure by using pre-defined linguistic expressions. They are modeled by trapezoidal type-1 fuzzy sets. The fuzzy value of each considered dimension is calculated as a sum of the fuzzy values of all of the identified failures under the considered dimension. By applying the defuzzification procedure, and according to the fuzzy rules (Belohlavek \& Klir, 2001), the fuzzy values of dimensions are described by crisp values. In this way, the framework for the application of the FMEA analysis in the information system domain was developed.

In the paper by A. C. F. Guimaraes et al (2011), the authorsemployed the FMEA analysis for the estimation of the digital system safety (feedwater systems) in nuclear power plants. The analysis developed in this paper is based on the conventional FMEA, where the RPN (Risk Priority Number) is calculated as the multiplication of the $\mathrm{O}, \mathrm{S}$ and $\mathrm{D}$ factors. For each 
considered digital controller, an RPN is determined. According to the rank of the obtained RNP values, the priority of the failures and the priority of the actions are determined, which need to be implemented for the purpose of eliminating these failures at the level of each controller. A comparison of the RPN values obtained in two manners is also performed. The considered values are determined by using: standard measure scales, and the Expert's estimations modeled by applying the fuzzy If-Then rules (Zadeh, 1992). The authors have concluded that the fuzzy approach is better than simple data collecting from records and by applying the traditional FMEA measure scales because this approach combines the knowledge and experience of experts, and can be better in the case of the unreliability of the data obtained from the records and the values of the analyzed parameters. One of the most important advantages of this approach is the simplicity of obtaining values for each $\operatorname{RPN}$ factor $(\mathrm{O}$, $S$ and $D)$, which is very complex to do in the standard approach.

The use of the FMEA analysis is, among other things, based on the assumption that $\mathrm{S}, \mathrm{O}$ and $\mathrm{D}$ have the same relative importance. According to the results of the best practice in any economy domain, this fact is not always quite exact. Respecting this fact, in order to improve decision-making, many authors consider the integration of the FMEA with the multi-criteria optimization methods necessary to perform (Song et al, 2014; Liu et al, 2016). In the papers by H. C. Liu et al (2015) and H. C. Liu et al (2016), the authors developed a new model for failure priority determination, which is based on the FMEA framework, and is implemented through three phases. In Phase One, the identification of the ways of a failure occurrence is performed using by applying the VIKOR method (Opricović \& Tzeng, 2004). In Phase Two, an influential relation map is created by using DEMATEL. In Phase Three, the authors use the AHP method (Saaty, 1990) for the determination of weights for each identified failure. In the paper by W. Song et al (2014), the integration of the TOPSIS method and the FMEA analysis is performed. All of the existing uncertainties are described by the rough sets theory (Pawlak, 1982). This model mainly lacks a limited possibility of being applied in practice because it requires additional expertise when the rough sets theory is concerned. In H. C.
Liu et al (2015), uncertainties are modeled into S, O, or D by applying Interval-Valued Intuitionistic Fuzzy Sets. A Multi-Attributive Border Approximation Area Comparison is used for ranking the manners in which failures occur. In the paper by R. Aslani et al (2014), the weights of S, O, and D are presented by applying the fuzzy AHP (Chang, 1996). These authors suggest a new procedure for the calculation of the RPN. According to the calculated RPN values, the rank of such identified failures is given. A. C. Kutlu and M. Ekmekcioglu (2012) have integrated the fuzzy AHP and the fuzzy TOPSIS methods, so that the weights $\mathrm{S}, \mathrm{O}$ and $\mathrm{D}$ are determined by using the fuzzy AHP (Aslani et al, 2014), and the rank of failures is determined by applying the fuzzy TOPSIS method. Imprecise and uncertain data are described by triangular type-1 fuzzy numbers.

In this paper, a new FMEA-framework-based multicriteria optimization model for ranking failures is developed. The severity index is considered from the two aspects: the quality and the cost. The authors of this paper consider that the proposed scale can be used to determine the severity of the consequences occurring due to the realization of failures in the IT sector with sufficient accuracy.

The weights of S, O, and D are determined by applying the BWM (Rezaei, 2015). Compared to other methods, e.g. to the AHP (Saaty, 1990), the BWM method has certain advantages, such as: the logical framework of the BWM is closer to the human way of thinking than the AHP method, for which reason this method is more useful for solving problems in practice. Therefore, the determination of weights by using the BWM method can be said to be simpler, clearer and more precise. The rank of identified failures is determined by using the TOPSIS method (Kutlu \& Ekmekcioglu, 2012; Song et al, 2014).

\section{THE PROPOSED MODEL}

The analysis of the failures that can occur in software products is conducted based on the criteria defined according to the FMEA. In general, possible failures can formally be presented by a set of indices 
$\gamma=\{1, \ldots, k, \ldots, K\}$. The index for a criterion is denoted as a small $\mathrm{k}$, and the capital $K$ is the total number of the considered criteria. In this case, the treated criteria are severity, occurrence and possible detection. All the identified failures can be formally presented as $G=\{1, \ldots, g, \ldots, G\}$. The failure index is denoted as a small $g, g=1, . ., G$. The total number of failures is denoted as the capital $G$.

The treated problem can be stated as a multi-criteria optimization (MCDM) task. The relative importance of the risk factors is assessed by the decision-maker, whose assessments are based on the literature data and the results of good practice and who uses the standard measurement scale (Saaty, 1990). By applying the BWM (Rezaei, 2015), the optimal risk factor weights are calculated. The elements of the decision matrix represent the values of the criteria obtained by the decision-maker's rating and the evidence data. The decision-makers base their assessments on the scales defined in this paper. The authors of this paper have proposed the scales for the information technologies sector. The rank of possible failures may be given by using the conventional MCDM method. In this paper, the authors suggest that the TOPSIS method should be used because it has a wide application in solving the problem of failure ranking.

The quality severity index, the cost safety index, the index of error occuerrence and the possibility of failure detection are assessed in accordance with the proposed scales presented in following tables (Table $1,2,3$ and 4$)$.

Table 1 The scenario-based table for the quality severity quality index

\begin{tabular}{c|l}
\hline Grade & Linguistic expressions \\
\hline 1 & Without an impact on the quality \\
2 & A very low impact on the quality \\
3 & A low impact on the quality \\
4 & A medium impact on the quality \\
5 & A high impact on the quality \\
6 & A very high impact on the quality \\
7 & An extremely high impact on the quality \\
\hline
\end{tabular}

Source: Authors
Table 2 The scenario-based table for the cost severity quality index

\begin{tabular}{c|l}
\hline Grade & Linguistic expressions \\
\hline 1 & Very low costs \\
2 & Low costs \\
3 & Medium costs \\
4 & High costs \\
5 & Very high costs \\
\hline
\end{tabular}

Source: Authors

Table 3 The scenario-based table for occurrence

\begin{tabular}{c|l}
\hline Grade & Linguistic expressions \\
\hline 1 & Very rarely \\
2 & Rarely \\
3 & Periodically \\
4 & Frequently \\
5 & Very frequently \\
\hline
\end{tabular}

Source: Authors

Table 4 The scenario-based table for detection

\begin{tabular}{c|l}
\hline Grade & Linguistic expressions \\
\hline 1 & Not possible to detect \\
2 & An extremely low possibility of detection \\
3 & A very low possibility of detection \\
4 & A low possibility of detection \\
5 & A medium-low possibility of detection \\
6 & A medium-high possibility of detection \\
7 & A high possibility of detection \\
8 & A very high possibility of detection \\
9 & An extremely high possibility of detection \\
\hline
\end{tabular}

Source: Authors

\section{The Proposed Algorithm}

The algorithm of the proposed model is presented as follows: 
Step 1. Determine the best (the most important) and the worst (the least important) risk factor.

Step 2. Determine the preference of the best risk factor over all the other risk factors. Formally, it can be written as the matrix $A_{B}=\left[a_{b 1^{\prime}}, \ldots a_{b k^{\prime}} \ldots, a_{B K}\right]_{1 x K}$. The preference of the worst risk factor over all the other risk factors is similarly defined and presented by the matrix $A_{W}=\left[a_{1 W}, \ldots a_{k W}, \ldots, a_{K W}\right]_{1 x K}$. The values of the constructed matrices are defined in a common measurement scale (Saaty, 1990).

Step 3. The calculation of the optimal risk factors weights can be stated as a linear programming problem:

The objective function

$$
\min \max _{k}\left\{\left|\frac{w_{B}}{w_{k}}-a_{B k}\right|,\left|\frac{w_{k}}{w_{W}}-a_{k W}\right|\right\}
$$

s.t.

$\sum_{k=1}^{K} w_{k}=1$

$w_{k} \geq 0, k=1, . ., K$

Step 4. Transform the constructed LP model in the following LP problem suitable for the use of the simplex method:

$$
\min \{\varsigma\}
$$

s.t.

$\left|\frac{w_{B}}{w_{k}}-a_{B k}\right| \leq \varsigma, k=1, . ., K$

$\left|\frac{w_{k}}{w_{W}}-a_{k W}\right| \leq \varsigma, k=1, . ., K$

$\sum_{k=1}^{K} w_{k}=1$

$w_{k} \geq 0, k=1, . ., K$
Step 5. By solving the problem (Eq. 2), the optimal weights vector is obtained:

$$
\left[W_{1}^{*}, \ldots, w_{k}^{*}, \ldots, w_{K}{ }^{*}\right]_{1 x K^{\prime}} \quad k=1, \ldots, K
$$

Step 6. The quality severity index, $S_{g 1}$, the cost severity index, $S_{g 2}$ the failure occurrence index, $O_{g^{\prime}}$ and the index of a possibility of detection, $D_{g}$, at the level of each failure $g, g=1, . ., G$ are determined according to the proposed scales.

Step 7. Calculate the overall severity index for each failure $g, g=1, . ., G$ by using the averaging method:

$$
S_{g}=\frac{1}{2} \cdot\left(S_{g 1}+S_{g 2}\right)
$$

Step 8. Determine the positive-ideal solution (PIS), $v_{k}^{+}$, and the negative-ideal solution (NIS), $v_{k}^{-}$, for all of the criteria:

$$
v_{k}^{+}=\max _{g=1, . ., G} r_{g k}, \quad v_{k}^{-}=\max _{g=1, . ., G} r_{g k}
$$

where $r_{g k}=S_{g}, O_{g}, D_{g}, g=1, \ldots, G$

Step 9. Calculate separation measures.

$$
d_{g}^{+}=\sum_{k=1}^{K} w_{k} \cdot\left|v_{k}^{+}-r_{g k}\right|, d_{g}^{-}=\sum_{k=1}^{K} w_{k} \cdot\left|v_{k}^{-}-r_{g k}\right|(6)
$$

Step 10. Calculate the coefficient of relative closeness to the ideal solution, defined as:

$$
c_{g}=\frac{d_{g}^{-}}{d_{g}^{-}+d_{g}^{+}}
$$

Step 11. Failures are ranked according to the level of trust in the descending order.

Step 12. The priority of the management initiatives corresponds to the obtained rank. 


\section{AN ILLUSTRATIVE EXAMPLE}

The developed method is tested on the data obtained from the CIM center (Computer Integrated Manufacturing) located at the Faculty of Engineering in Kragujevac. In this center, the business process management models and the correspondent software are being developed. The failures that occur in the software development process and that can be identified in the software testing process are obtained based on the data generated from the records, as well as on the basis of the knowledge of and the estimations made by the software engineers working in this center.

The estimations of severity, occurrence and detection values for the identified failures are shown in Table 5 .

Table 5 The estimations of the severity, occurrence and detection values for each identified failure

\begin{tabular}{|c|c|c|c|c|}
\hline \multirow{2}{*}{ Failure } & \multicolumn{2}{|c|}{$S$} & \multirow{2}{*}{0} & \multirow{2}{*}{$\mathrm{D}$} \\
\hline & Q & C & & \\
\hline $\begin{array}{l}\text { Software inflexibility to different } \\
\text { operative systems }\end{array}$ & 5 & 4 & 3 & 6 \\
\hline Upgrade inability & 6 & 5 & 2 & 7 \\
\hline $\begin{array}{l}\text { Inability to meet customer } \\
\text { demands and dysfunctionality }\end{array}$ & 7 & 5 & 4 & 8 \\
\hline $\begin{array}{l}\text { Inadequate graphical user interface } \\
\text { design }\end{array}$ & 5 & 2 & 2 & 2 \\
\hline $\begin{array}{l}\text { Low operative performance and } \\
\text { bagging problems during execution }\end{array}$ & 6 & 4 & 5 & 7 \\
\hline Total software blockade & 7 & 4 & 1 & 9 \\
\hline
\end{tabular}

Source: Authors

By applying the proposed algorithm (Step 1 to Step 5), the weights of severity, occurrence and detection are determined.

$A_{B}=[1,7,4]$

$A_{\mathrm{W}}=[1,7,4]$

The weights determination problem can be expressed by the LP task. $\min \{0.145]\}$

s.t.

$\left|\frac{w_{1}}{w_{2}}-7\right| \leq 0.145$

$\left|\frac{w_{1}}{w_{3}}-4\right| \leq 0.145$

$\left|\frac{w_{2}}{w_{3}}-2\right| \leq 0.145$

$w_{1}+w_{2}+w_{3}=1$

So, the obtained optimal weight vector is

(0.7209, 0.1052, 0.1739)

According to the proposed algorithm (Step 6 to Step $8)$, the decision matrix is constructed and PIS and NIS are presented (Table 6).

Table 6 The decision matrix, PIS and NIS

\begin{tabular}{l|ccc}
\hline Failure & S & O & D \\
\hline $\begin{array}{l}\text { Software inflexibility to different } \\
\text { operative systems }\end{array}$ & 4.5 & 3 & 6 \\
$\begin{array}{l}\text { Upgrade inability } \\
\text { Inability to meet customer demands }\end{array}$ & 6.5 & 2 & 7 \\
$\begin{array}{l}\text { and dysfunctionality } \\
\text { Inadequate graphical user interface }\end{array}$ & 3.5 & 2 & 2 \\
design & & & 8 \\
Low operative performance and & 5 & 5 & 7 \\
bagging problems during execution & 5.5 & 1 & 9 \\
Total software blockade & 6 & 5 & 9 \\
PIS & 3.5 & 1 & 2 \\
NIS & & & \\
\hline
\end{tabular}

Source: Authors

The separation measurements are calculated by applying Eq. (6), and the coefficient of relative closeness to the ideal solution for each identified failure is calculated by applying Eq. (7). This 
procedure is illustrated by the following example:

$d_{1}^{+}=0.7209 \cdot|6-4.5|+0.1052 \cdot|5-3|+0.1739 \cdot|9-6|=6.5094$

$d_{1}^{-}=0.7209 \cdot|3.5-4.5|+0.1052 \cdot|1-3|+0.1739 \cdot|2-6|=1.6269$

$c_{1}=\frac{1.6269}{1.6269+6.5094}=0.1999$

The coefficient of relative closeness to the ideal solution is calculated in the same manner and presented in Table 7. According to the calculated values, the rank of the failures is determined.

Table 7 The values of the relative closeness coefficient and the failures rank

\begin{tabular}{|c|c|c|c|c|}
\hline Failure & $d_{i}^{+}$ & $d_{i}^{-}$ & $c_{i}$ & Rank \\
\hline $\begin{array}{l}\text { Software } \\
\text { inflexibility } \\
\text { to different } \\
\text { operative } \\
\text { systems }\end{array}$ & 6.5094 & 1.6269 & 0.1999 & 5 \\
\hline $\begin{array}{l}\text { Upgrade } \\
\text { inability }\end{array}$ & 1.0238 & 1.7209 & 0.6269 & 4 \\
\hline $\begin{array}{l}\text { Inability to } \\
\text { meet customer } \\
\text { demands and } \\
\text { dysfunctionality }\end{array}$ & 0.2791 & 3.1613 & 0.9189 & 1 \\
\hline $\begin{array}{l}\text { Inadequate } \\
\text { graphical user } \\
\text { interface design }\end{array}$ & 3.3352 & 0.1052 & 0.0306 & 6 \\
\hline $\begin{array}{l}\text { Low operative } \\
\text { performance } \\
\text { and bagging } \\
\text { problems during } \\
\text { execution }\end{array}$ & 1.0687 & 2.3716 & 0.6893 & 3 \\
\hline $\begin{array}{l}\text { Total software } \\
\text { blockade }\end{array}$ & 0.7811 & 2.6593 & 0.7729 & 2 \\
\hline
\end{tabular}

Source: Authors

The first-ranked failure in the given ranking is the inability to meet customer demands and dysfunctionality, and it has the biggest impact on software usability. The second-ranked failure in the given ranking is the total software blockade. It is clear that software engineers primarily need to undertake activities for the elimination of these two failures. Some of the activities are implicative of finding oversights in the software development process that lead to the occurrence of these failures. Sometimes, these oversights can be eliminated if they are minor. It is not a rare case that a program must be written from the very beginning, i.e. it must be subjected to the execution of software re-engineering. It is necessary that an updated software version should be tested so as to determine the (no)existence of such failures. The third- and fourth-ranked failures in the giving ranking are the low operative performance and bagging problems during execution failure, and the upgrade inability failure, respectively. According to the obtained relative closeness coefficient values, these failures can be said to have an almost similar impact on software usability, which further means that the activities for the elimination of these failures should simultaneously be carried out. The failure ranked the last is the inadequate graphic user interface design, with a significantly low impact on the software quality.

\section{CONCLUSION}

It is clear that the assessment and determination of the priority of failures, as well as the existence of a number of issues, take an important place. In this paper, a novel approach to the assessment and ranking of failures in the IT sector is presented. Based on the obtained results, the decision-maker may define the appropriate activities that should lead to a decrease in the risk of delivering a product with a failure to the customer, which further propagates long term sustainability. The proposed model was tested against real-life data.

- The key results of this research study are as follows:

- The new tables (related to severity and detection) for the IT sector are created.

- The new cost severity index is generated. 
- The relative importance of the defined severity, occurrence and detection is determined by applying the BWM method.

- All the changes, inclusive of the changes in the number of failures, can easily be incorporated into the model.

The considered problem may be described by using the formal language as an MCDM problem enabling the determination of the failure rank in an exact manner, for which reason the first hypothesis has been proven.

Activity undertaking in the shown order may bring about a reduction in the time spent and the cost incurred in the software updating process. In this manner, the second hypothesis has been proven.

Beside the aforementioned various advantages of the proposed model for the selection of failures, there are certain limitations pertaining to it, namely:

- The new approach is complex and timeconsuming, just like the other models combining the MDCM and the FMEA methods. Therefore, a certain automatized solution is needed in order to overcome this problem.

- The rating of the relative importance of severity, occurrence and detection, as well as their values, depends on decision-makers' knowledge and experiences.

- Although, sometimes, the effect of a failure does not lead to a safety consequence, this factor is still taken into consideration in the course of risk evaluation.

At the same time, the proposed model can be applied to the assessment and ranking of failures in IT companies operating in a real environment.

A further research study should include new aspects in the severity index.

\section{ACKNOWLEDGEMENTS}

This paper was supported by the Croatian Science Foundation under the project entitled "Innovative Smart Enterprise - INSENT" (1353) and by the European Commission under the "Green-Tech-WB: Smart and Green Technologies for Innovative and Sustainable Societies in Western Balkans" Erasmus Mundus Project (551984-EM-1-2014-1-ES-ERA MUNDUS-EMA2).

\section{REFERENCES}

Abdelgawad, M., \& Fayek, A. R. (2010). Risk management in the construction industry using combined fuzzy FMEA and fuzzy AHP. Journal of Construction Engineering and Management, 136(9), 1028-1036. doi.org/10.1061/(ASCE) C0.1943-7862.0000210

Aslani, R., Feili, H., \& Javanshir, H. (2014). A hybrid of fuzzy FMEA-AHP to determine factors affecting alternator failure causes. Management Science Letters, 4(9), 1981-1984. doi:10.5267/j.msl.2014.8.024

Banduka, N., Tadić, D., Mačužić, I., Crnjac, M. (2018). Extened Process Failure Mode and Effect Analysis (PFMEA) for automotive industry: The FSQC-PFMEA, acceptged for publishing for tom Advances in Production Engineering $\mathcal{E}$ Management.

Belohlavek, R., \& Klir, G. J. (2011). Concepts and Fuzzy Logic. MIT Press.

Carmignani, G. (2009). An integrated structural framework to cost-based FMECA: The priority-cost FMECA. Reliability Engineering \& System Safety, 94(4), 861-871.

Chang, D. Y. (1996). Applications of the extent analysis method on fuzzy AHP. European journal of operational research, 95(3), 649-655.

Dedrick, J., Kraemer, K. L., \& Shih, E. (2013). Information technology and productivity in developed and developing countries. Journal of Management Information Systems, 30(1), 97-122.

Gabus, A., \& Fontela, E. (1972). World Problems, an Invitation to Further Thought Within the Framework of DEMATEL. Geneva, Switzerland: Battelle Geneva Research Center. 
Guimarães, A. C. F., Lapa, C. M. F., \& de Lourdes Moreira, M. (2011). Fuzzy methodology applied to probabilistic safety assessment for digital system in nuclear power plants. Nuclear Engineering and Design, 241(9), 3967-3976.

Hwang, C. L., \& Yoon, K. (1981). Methods for multiple attribute decision making. In Multiple attribute decision making (pp. 58191). Springer, Berlin, Heidelberg.

Kutlu, A. C., \& Ekmekçioğlu, M. (2012). Fuzzy failure modes and effects analysis by using fuzzy TOPSIS-based fuzzy AHP. Expert Systems with Applications, 39(1), 61-67.

Liu, H. C., Qin, J. T., Mao, L. X., \& Zhang, Z. Y. (2015). Personnel Selection Using Interval 2-Tuple Linguistic VIKOR Method. Human Factors and Ergonomics in Manufacturing \& Service Industries, 25(3), 370-384.

Liu, H. C., You, J. X., Li, P., \& Su, Q. (2016). Failure mode and effect analysis under uncertainty: An integrated multiple criteria decision making approach. IEEE Transactions on Reliability, 65(3), 1380-1392.

Opricovic, S., \& Tzeng, G. H. (2004). Compromise solution by MCDM methods: A comparative analysis of VIKOR and TOPSIS. European journal of operational research, 156(2), 445455.
Papaioannou, S. K., \& Dimelis, S. P. (2007). Information technology as a factor of economic development: Evidence from developed and developing countries. Economics of Innovation and New Technology, 16(3), 179-194.

Pawlak, Z. (1982). Rough sets. International journal of computer E information sciences, 11(5), 341-356.

Rezaei, J. (2015). Best-worst multi-criteria decision-making method. Omega, 53, 49-57.

Saaty, T. L. (1990). An exposition of the AHP in reply to the paper "remarks on the analytic hierarchy process". Management science, 36(3), 259-268.

Signor, M. C. (2002). The failure-analysis matrix: A Kinder, gentler alternative to FMEA for information systems. In Reliability and Maintainability Symposium, 2002. Proceedings. Annual (pp. 173-177). IEEE.

Silva, M. M., de Gusmão, A. P. H., Poleto, T., e Silva, L. C., \& Costa, A. P. C. S. (2014). A multidimensional approach to information security risk management using FMEA and fuzzy theory. International Journal of Information Management, 34(6), 733-740. 
Marin Peko is a Ph.D. student at the Faculty of Electrical Engineering, Mechanical Engineering and Naval Architecture, University of Split, Split, The Republic of Croatia. His field of research includes computer science and ICT technology.

Nikola Komatina is a research assistant and a first-year Ph.D. student at the Faculty of Engineering, University of Kragujevac, Kragujevac, The Republic of Serbia. His field of research includes operational research and supply-chain management.

Nikola Banduka is a Ph.D. candidate at the Faculty of Engineering, University of Kragujevac, Kragujevac, The Republic of Serbia, and the Faculty of Electrical Engineering, Mechanical Engineering and Naval Architecture, University of Split, Split, The Republic of Croatia. His field of research includes industrial engineering and risk analysis.

Marina Crnjac is a Ph.D. candidate at the Faculty of Electrical Engineering, Mechanical Engineering and Naval Architecture, University of Split, Split, The Republic of Croatia. Her field of research includes industrial engineering. 


\title{
THE ASSESSMENT AND RANKING OF FAILURES IN THE INFORMATION TECHNOLOGY INDUSTRY BASED ON FMEA AND MCDM
}

\author{
Marin Peko', Nikola Komatina*2, Nikola Banduka ${ }^{1,2}$ and Marina Crnjac ${ }^{2}$ \\ ${ }^{1}$ Faculty of Electrical Engineering, Mechanical Engineering and Naval Architecture, University of \\ Split, Split, The Republic of Croatia \\ ${ }^{2}$ Faculty of Engineering, University of Kragujevac, Kragujevac, The Republic of Serbia
}

In the course of global trends, the development and application of information technologies have emerged as a valuable source of the economy at both the micro and the macro levels. According to the results of the best practice, the application of a piece of software with failures is known to possibly to serious consequences. The analysis and elimination of potential failures in commercial software is the problem that represents one of engineers' most important tasks. In this paper, a new integrated model for the evaluation and ranking of software failures is proposed. The cost aspect is integrated into the traditional severity index. The assessment of the severity indices, as well as a possibility of detection, is based on the Failure Mode and Effects Analysis - FMEA framework. The weights of the overall severity index, the occurrence of failures, and the possibilities of detection are calculated by applying the best-worst method. The determination of the rank of the identified failures is given by applying conventional Technique for Order of Preference by Similarity to Ideal Solution - TOPSIS. The priority of the activities that are undertaken in order to eliminate the identified failures corresponds to the obtained rank of the failures. The proposed model is illustrated by real-life data.

Keywords: software development, Failure Mode and Effects Analysis, Best-Worst method, Technique for Order of Preference by Similarity to Ideal Solution

JEL Classification: C6, 12

\section{INTRODUCTION}

The development of the information technology (IT) sector has significantly been changing the habits and

* Correspondence to: N. Komatina, Faculty of Engineering, University of Kragujevac, Sestre Janjic 6, 34000 Kragujevac, The Republic of Serbia; e-mail: nkomatina@kg.ac.rs needs of people. Nowadays, people are completely surrounded by information technologies, starting from smartphones, computers, smart TVs, via other new-generation home appliances, to their jobs, where work is unimaginable without information technologies. Today, the information technology sector is one of the main drivers of the development 
of the economy (Papaioannou \& Dimelis, 2007) because the products and services in this domain are very much required on the market. Many countries highlight the IT sector as one of the pillars of their economic development and invest in the education of the necessary staff (Dedrick, Kraemer \& Shih, 2013).

According to the lean concept of enterprise management and the results of good practice, it is known that if the final product, a piece of software in this particular case, has a failure in itself and reaches the customer it can bring about catastrophic consequences to the company, such consequences reflecting in a decrease in the profit, lesser market competitiveness, a loss of customers, etc. Therefore, the identification, analysis and elimination of a failure which may be found on a piece of software as a product is one of the most important tasks of both programmers and other engineers from within IT companies.

One of the most- used methods for failure analysis is the Failure Mode and Effects Analysis (FMEA), primarily in the automotive and airline industries. In the literature, there are papers treating the problem of the failure analysis of products and processes in the IT sector based on the FMEA framework (Signor, 2002; Silva, de Gusmão, Poleto, e Silva \& Costa, 2014). In conventional FMEA, the rank of failures is obtained according to the Risk Priority Number (RPN), which on its part is obtained as a product of all of the three considered criteria (severity, occurrence and detection). For the automotive industry, the values of these criteria and the rules for undertaking corrective actions are defined by the Automotive Industry Agency Group. The RPN range is (1-1000), whereas the values of the severity, occurrence and detection criteria have a range of (1-10). Corrective actions should be undertaken at any time, but especially when the RPN value exceeds 100, or one of the risk indices value exceeds 8 .

In the conventional FMEA method, the severities of consequences are assessed by observing the quality aspect. Many authors think it is necessary to consider the other aspects, primarily the cost aspect (Carmignani, 2009; Abdelgawad \& Fayek,
2010; Banduka, Tadić, Mačužić \& Crnjac, 2018). Cost estimation is made by using new calculation formulas as in G. Carmignani (2009). In the paper of M. Abdelgawad and A. R. Fayek (2010), the overall severity index is considered with respect to the three dimensions, namely: the cost, the time, and the quality/scope. N. Banduka et al (2018), define a new scale for cost assessment.

On the other hand, in the traditional FMEA method, all of the considered criteria are assumed to have equal relative importance. With respect to the results of the best practice, this assumption can be said not to be completely accurate. Hence, many authors suggest that the values and the rank of failures should be stated as a multi-criteria optimization (MCDM) problem (Song, Ming, Wu \& Zhu, 2014; Liu, You, Li \& $\mathrm{Su}, 2016)$. This problem can be solved by using one or a combination of several MCDM methods. The most used methods are the Analytic Hierarchy Process - AHP, the Technique for Order of Preference by Similarity to Ideal Solution - TOPSIS, etc.

The subject of this research is the evaluation of potential failures in software used for business process management problems.

The aim of the research study is to develop a new multi-criteria optimization model based on the FMEA framework for the estimation and ranking of failures in the IT sector.

According to the defined goal, the following hypotheses can be formulated:

H1 The evaluation and ranking of failures can be performed in an exact manner.

H2 By using the proposed method, the priority of the activities that need to be employed in order to eliminate a possibility of delivering the final product with a failure to the customer is determined in an exact manner.

Every solution obtained in an exact manner is known to be less burdened with decision-makers' subjective assessments and can be considered as more precise. On the other hand, the use of resources (human, 
time-related and financial) for failure elimination is significantly reduced, which further leads to a reduction in business expenses, i.e. to an increase in a profit.

The instrumentarium used in this paper can be described as follows: the severities-based and detection scenarios are defined according to the relevant literature and the expert opinion; the relative importance of severity, occurrence and detection is determined by applying the Best-Worst method (Rezaei, 2015); the ranking of failures can be performed by applying the Technique for Order of Preference by Similarity to Ideal Solution (TOPSIS) method (Hwang \& Yoon, 1981).

This paper is organized in five sections. In Section Two, a literature review of the relevant literature in the domain of the FMEA method and the MCDM method based on the FMEA framework for the assessment and selection of failures is given. Section Three presents the proposed model. In Section Four, the proposed model is tested by means of the literature data, whereas the conclusion is given in Section Five.

\section{LITERATURE REVIEW}

In the literature, there are a few papers addressing the problem of failure priority determination, which may occur in different products and in different sectors of information technology processes. Furthermore, a short analysis of the considered papers is shown, the main topic of these papers being the application of the FMEA analysis in the information technology domain.

M. C. Signor (2002) developed a model for risk priority determination, i.e. the Failure-Analysis Matrix (FAM), which is conceived as an alternative to the FMEA analysis in the information technology domain. The FAM matrix is based on the detection of the key failures, after which all potential solutions to the elimination of one single failure at least are necessary to find. Then, such alternative solutions are presented in rows, whereas the estimated costs of such solutions, the priority of a solution and a reduction in defects expressed in percentages are given in columns. The application of the created matrix reflects in the determination of the extent to which each such solution is effective when the elimination of each such failure is concerned. It depends on the extent to which the considered solution is good for the treatment of the considered failure, and such reduction in defects expressed in percentages is determined. It should be noted that the FAM matrix is significantly simpler and less extensive in comparison with the FMEA. That can be marked as the main advantage of FAM in comparison with the FMEA. When the FMEA is used, each potential failure is assumed to be taken into consideration, whereas in the FAM matrix, only a few failures with the biggest impact are considered. This is a significant disadvantage of the FAM matrix.

M. M. Silva et al (2014), employed the FMEA analysis and the fuzzy sets theory in order to identify and reduce the occurrence of failures in the information safety and data protection domain(s). By this approach, the five basic dimensions of information safety are analyzed, namely: access to information and systems, communication security, the infrastructure, security management, and secure information systems development. Each of these dimensions includes several (from 3 to 6) identified failure modes. Experts estimate the Occurrence, Severity and Detection of each such identified failure by using pre-defined linguistic expressions. They are modeled by trapezoidal type-1 fuzzy sets. The fuzzy value of each considered dimension is calculated as a sum of the fuzzy values of all of the identified failures under the considered dimension. By applying the defuzzification procedure, and according to the fuzzy rules (Belohlavek \& Klir, 2001), the fuzzy values of dimensions are described by crisp values. In this way, the framework for the application of the FMEA analysis in the information system domain was developed.

In the paper by A. C. F. Guimaraes et al (2011), the authorsemployed the FMEA analysis for the estimation of the digital system safety (feedwater systems) in nuclear power plants. The analysis developed in this paper is based on the conventional FMEA, where the RPN (Risk Priority Number) is calculated as the multiplication of the $\mathrm{O}, \mathrm{S}$ and $\mathrm{D}$ factors. For each 
considered digital controller, an RPN is determined. According to the rank of the obtained RNP values, the priority of the failures and the priority of the actions are determined, which need to be implemented for the purpose of eliminating these failures at the level of each controller. A comparison of the RPN values obtained in two manners is also performed. The considered values are determined by using: standard measure scales, and the Expert's estimations modeled by applying the fuzzy If-Then rules (Zadeh, 1992). The authors have concluded that the fuzzy approach is better than simple data collecting from records and by applying the traditional FMEA measure scales because this approach combines the knowledge and experience of experts, and can be better in the case of the unreliability of the data obtained from the records and the values of the analyzed parameters. One of the most important advantages of this approach is the simplicity of obtaining values for each $\mathrm{RPN}$ factor $(\mathrm{O}$, $\mathrm{S}$ and $\mathrm{D})$, which is very complex to do in the standard approach.

The use of the FMEA analysis is, among other things, based on the assumption that $\mathrm{S}, \mathrm{O}$ and $\mathrm{D}$ have the same relative importance. According to the results of the best practice in any economy domain, this fact is not always quite exact. Respecting this fact, in order to improve decision-making, many authors consider the integration of the FMEA with the multi-criteria optimization methods necessary to perform (Song et al, 2014; Liu et al, 2016). In the papers by H. C. Liu et al (2015) and H. C. Liu et al (2016), the authors developed a new model for failure priority determination, which is based on the FMEA framework, and is implemented through three phases. In Phase One, the identification of the ways of a failure occurrence is performed using by applying the VIKOR method (Opricović \& Tzeng, 2004). In Phase Two, an influential relation map is created by using DEMATEL. In Phase Three, the authors use the AHP method (Saaty, 1990) for the determination of weights for each identified failure. In the paper by W. Song et al (2014), the integration of the TOPSIS method and the FMEA analysis is performed. All of the existing uncertainties are described by the rough sets theory (Pawlak, 1982). This model mainly lacks a limited possibility of being applied in practice because it requires additional expertise when the rough sets theory is concerned. In H. C.
Liu et al (2015), uncertainties are modeled into S, O, or D by applying Interval-Valued Intuitionistic Fuzzy Sets. A Multi-Attributive Border Approximation Area Comparison is used for ranking the manners in which failures occur. In the paper by R. Aslani et al (2014), the weights of S, O, and D are presented by applying the fuzzy AHP (Chang, 1996). These authors suggest a new procedure for the calculation of the RPN. According to the calculated RPN values, the rank of such identified failures is given. A. C. Kutlu and M. Ekmekcioglu (2012) have integrated the fuzzy AHP and the fuzzy TOPSIS methods, so that the weights $\mathrm{S}, \mathrm{O}$ and $\mathrm{D}$ are determined by using the fuzzy AHP (Aslani et al, 2014), and the rank of failures is determined by applying the fuzzy TOPSIS method. Imprecise and uncertain data are described by triangular type-1 fuzzy numbers.

In this paper, a new FMEA-framework-based multicriteria optimization model for ranking failures is developed. The severity index is considered from the two aspects: the quality and the cost. The authors of this paper consider that the proposed scale can be used to determine the severity of the consequences occurring due to the realization of failures in the IT sector with sufficient accuracy.

The weights of S, O, and D are determined by applying the BWM (Rezaei, 2015). Compared to other methods, e.g. to the AHP (Saaty, 1990), the BWM method has certain advantages, such as: the logical framework of the BWM is closer to the human way of thinking than the AHP method, for which reason this method is more useful for solving problems in practice. Therefore, the determination of weights by using the BWM method can be said to be simpler, clearer and more precise. The rank of identified failures is determined by using the TOPSIS method (Kutlu \& Ekmekcioglu, 2012; Song et al, 2014).

\section{THE PROPOSED MODEL}

The analysis of the failures that can occur in software products is conducted based on the criteria defined according to the FMEA. In general, possible failures can formally be presented by a set of indices 
$\gamma=\{1, \ldots, k, \ldots, K\}$. The index for a criterion is denoted as a small $\mathrm{k}$, and the capital $K$ is the total number of the considered criteria. In this case, the treated criteria are severity, occurrence and possible detection. All the identified failures can be formally presented as $G=\{1, \ldots, g, \ldots, G\}$. The failure index is denoted as a small $g, g=1, . ., G$. The total number of failures is denoted as the capital $G$.

The treated problem can be stated as a multi-criteria optimization (MCDM) task. The relative importance of the risk factors is assessed by the decision-maker, whose assessments are based on the literature data and the results of good practice and who uses the standard measurement scale (Saaty, 1990). By applying the BWM (Rezaei, 2015), the optimal risk factor weights are calculated. The elements of the decision matrix represent the values of the criteria obtained by the decision-maker's rating and the evidence data. The decision-makers base their assessments on the scales defined in this paper. The authors of this paper have proposed the scales for the information technologies sector. The rank of possible failures may be given by using the conventional MCDM method. In this paper, the authors suggest that the TOPSIS method should be used because it has a wide application in solving the problem of failure ranking.

The quality severity index, the cost safety index, the index of error occuerrence and the possibility of failure detection are assessed in accordance with the proposed scales presented in following tables (Table 1, 2, 3 and 4).

Table 1 The scenario-based table for the quality severity quality index

\begin{tabular}{c|l}
\hline Grade & Linguistic expressions \\
\hline 1 & Without an impact on the quality \\
2 & A very low impact on the quality \\
3 & A low impact on the quality \\
4 & A medium impact on the quality \\
5 & A high impact on the quality \\
6 & A very high impact on the quality \\
7 & An extremely high impact on the quality \\
\hline
\end{tabular}

Source: Authors
Table 2 The scenario-based table for the cost severity quality index

\begin{tabular}{c|l}
\hline Grade & Linguistic expressions \\
\hline 1 & Very low costs \\
2 & Low costs \\
3 & Medium costs \\
4 & High costs \\
5 & Very high costs \\
\hline
\end{tabular}

Source: Authors

Table 3 The scenario-based table for occurrence

\begin{tabular}{c|l}
\hline Grade & Linguistic expressions \\
\hline 1 & Very rarely \\
2 & Rarely \\
3 & Periodically \\
4 & Frequently \\
5 & Very frequently \\
\hline
\end{tabular}

Source: Authors

Table 4 The scenario-based table for detection

\begin{tabular}{c|l}
\hline Grade & Linguistic expressions \\
\hline 1 & Not possible to detect \\
2 & An extremely low possibility of detection \\
3 & A very low possibility of detection \\
4 & A low possibility of detection \\
5 & A medium-low possibility of detection \\
6 & A medium-high possibility of detection \\
7 & A high possibility of detection \\
8 & A very high possibility of detection \\
9 & An extremely high possibility of detection \\
\hline
\end{tabular}

Source: Authors

\section{The Proposed Algorithm}

The algorithm of the proposed model is presented as follows: 
Step 1. Determine the best (the most important) and the worst (the least important) risk factor.

Step 2. Determine the preference of the best risk factor over all the other risk factors. Formally, it can be written as the matrix $A_{B}=\left[a_{b 1^{\prime}}, \ldots a_{b k^{\prime}}, \ldots, a_{B K}\right]_{1 x K^{*}}$. The preference of the worst risk factor over all the other risk factors is similarly defined and presented by the matrix $A_{W}=\left[a_{1 W}, \ldots a_{k W}, \ldots, a_{K W}\right]_{1 x K}$. The values of the constructed matrices are defined in a common measurement scale (Saaty, 1990).

Step 3. The calculation of the optimal risk factors weights can be stated as a linear programming problem:

The objective function

$$
\min \max _{k}\left\{\left|\frac{w_{B}}{w_{k}}-a_{B k}\right|,\left|\frac{w_{k}}{w_{W}}-a_{k W}\right|\right\}
$$

s.t.

$\sum_{k=1}^{K} w_{k}=1$

$w_{k} \geq 0, k=1, . ., K$

Step 4. Transform the constructed LP model in the following LP problem suitable for the use of the simplex method:

$$
\min \{\varsigma\}
$$

s.t.

$\left|\frac{w_{B}}{w_{k}}-a_{B k}\right| \leq \varsigma, k=1, . ., K$

$\left|\frac{w_{k}}{w_{W}}-a_{k W}\right| \leq \varsigma, k=1, . ., K$

$\sum_{k=1}^{K} w_{k}=1$

$w_{k} \geq 0, k=1, . ., K$
Step 5. By solving the problem (Eq. 2), the optimal weights vector is obtained:

$$
\left[W_{1}^{*}, \ldots, w_{k}^{*}, \ldots, w_{K}{ }^{*}\right]_{1 x K^{\prime}} \quad k=1, \ldots, K
$$

Step 6. The quality severity index, $S_{g 1}$, the cost severity index, $S_{g 2}$ the failure occurrence index, $O_{g^{\prime}}$ and the index of a possibility of detection, $D_{g}$, at the level of each failure $g, g=1, . ., G$ are determined according to the proposed scales.

Step 7. Calculate the overall severity index for each failure $g, g=1, . ., G$ by using the averaging method:

$$
S_{g}=\frac{1}{2} \cdot\left(S_{g 1}+S_{g 2}\right)
$$

Step 8. Determine the positive-ideal solution (PIS), $v_{k}^{+}$, and the negative-ideal solution (NIS), $v_{k}^{-}$, for all of the criteria:

$$
v_{k} \max _{g} r_{1, . ., G}, \quad v_{k}^{-}=\max _{g=1, . ., G} r_{g k}
$$

where $r_{g k}=S_{g}, O_{g}, D_{g}, g=1, \ldots, G$

Step 9. Calculate separation measures.

$$
d_{g}^{+}=\sum_{k=1}^{K} w_{k} \cdot\left|v_{k}^{+}-r_{g k}\right|, d_{g}^{-}=\sum_{k=1}^{K} w_{k} \cdot\left|v_{k}^{-}-r_{g k}\right|(6)
$$

Step 10. Calculate the coefficient of relative closeness to the ideal solution, defined as:

$$
c_{g}=\frac{d_{g}^{-}}{d_{g}^{-}+d_{g}^{+}}
$$

Step 11. Failures are ranked according to the level of trust in the descending order.

Step 12. The priority of the management initiatives corresponds to the obtained rank. 


\section{AN ILLUSTRATIVE EXAMPLE}

The developed method is tested on the data obtained from the CIM center (Computer Integrated Manufacturing) located at the Faculty of Engineering in Kragujevac. In this center, the business process management models and the correspondent software are being developed. The failures that occur in the software development process and that can be identified in the software testing process are obtained based on the data generated from the records, as well as on the basis of the knowledge of and the estimations made by the software engineers working in this center.

The estimations of severity, occurrence and detection values for the identified failures are shown in Table 5 .

Table 5 The estimations of the severity, occurrence and detection values for each identified failure

\begin{tabular}{l|cc|ccc}
\hline \multirow{2}{*}{ Failure } & \multicolumn{3}{|c|}{ S } & \multirow{2}{*}{ O } & D \\
\cline { 2 - 3 } & Q & C & & \\
\hline $\begin{array}{l}\text { Software inflexibility to different } \\
\text { operative systems }\end{array}$ & 5 & 4 & 3 & 6 \\
$\begin{array}{l}\text { Upgrade inability } \\
\begin{array}{l}\text { Inability to meet customer } \\
\text { demands and dysfunctionality }\end{array}\end{array}$ & 6 & 5 & 2 & 7 \\
$\begin{array}{l}\text { Inadequate graphical user interface } \\
\text { design }\end{array}$ & 5 & 2 & 4 & 8 \\
$\begin{array}{l}\text { Low operative performance and } \\
\text { bagging problems during execution }\end{array}$ & 6 & 4 & 5 & 7 \\
\begin{tabular}{l} 
Total software blockade \\
\hline
\end{tabular} & 7 & 4 & 1 & 9 \\
\hline
\end{tabular}

Source: Authors

By applying the proposed algorithm (Step 1 to Step 5), the weights of severity, occurrence and detection are determined.

$A_{B}=[1,7,4]$

$A_{\mathrm{w}}=[1,7,4]$

The weights determination problem can be expressed by the LP task. $\min \{0.145]\}$

s.t.

$\left|\frac{w_{1}}{w_{2}}-7\right| \leq 0.145$

$\left|\frac{w_{1}}{w_{3}}-4\right| \leq 0.145$

$\left|\frac{w_{2}}{w_{3}}-2\right| \leq 0.145$

$w_{1}+w_{2}+w_{3}=1$

So, the obtained optimal weight vector is

$(0.7209,0.1052,0.1739)$

According to the proposed algorithm (Step 6 to Step 8), the decision matrix is constructed and PIS and NIS are presented (Table 6).

Table 6 The decision matrix, PIS and NIS

\begin{tabular}{l|ccc}
\hline Failure & S & O & D \\
\hline $\begin{array}{l}\text { Software inflexibility to different } \\
\text { operative systems }\end{array}$ & 4.5 & 3 & 6 \\
$\begin{array}{l}\text { Upgrade inability } \\
\text { Inability to meet customer demands }\end{array}$ & 5.5 & 2 & 7 \\
$\begin{array}{l}\text { and dysfunctionality } \\
\text { Inadequate graphical user interface }\end{array}$ & 3.5 & 2 & 2 \\
$\begin{array}{l}\text { design } \\
\text { Low operative performance and }\end{array}$ & 5 & 5 & 7 \\
bagging problems during execution & 5.5 & 1 & 9 \\
Total software blockade & 6 & 5 & 9 \\
PIS & 3.5 & 1 & 2 \\
NIS
\end{tabular}

Source: Authors

The separation measurements are calculated by applying Eq. (6), and the coefficient of relative closeness to the ideal solution for each identified failure is calculated by applying Eq. (7). This 
procedure is illustrated by the following example:

$d_{1}^{+}=0.7209 \cdot|6-4.5|+0.1052 \cdot|5-3|+0.1739 \cdot|9-6|=6.5094$

$d_{1}^{-}=0.7209 \cdot|3.5-4.5|+0.1052 \cdot|1-3|+0.1739 \cdot|2-6|=1.6269$

$c_{1}=\frac{1.6269}{1.6269+6.5094}=0.1999$

The coefficient of relative closeness to the ideal solution is calculated in the same manner and presented in Table 7. According to the calculated values, the rank of the failures is determined.

Table 7 The values of the relative closeness coefficient and the failures rank

\begin{tabular}{|c|c|c|c|c|}
\hline Failure & $d_{i}^{+}$ & $d_{i}^{-}$ & $c_{i}$ & Rank \\
\hline $\begin{array}{l}\text { Software } \\
\text { inflexibility } \\
\text { to different } \\
\text { operative } \\
\text { systems }\end{array}$ & 6.5094 & 1.6269 & 0.1999 & 5 \\
\hline $\begin{array}{l}\text { Upgrade } \\
\text { inability }\end{array}$ & 1.0238 & 1.7209 & 0.6269 & 4 \\
\hline $\begin{array}{l}\text { Inability to } \\
\text { meet customer } \\
\text { demands and } \\
\text { dysfunctionality }\end{array}$ & 0.2791 & 3.1613 & 0.9189 & 1 \\
\hline $\begin{array}{l}\text { Inadequate } \\
\text { graphical user } \\
\text { interface design }\end{array}$ & 3.3352 & 0.1052 & 0.0306 & 6 \\
\hline $\begin{array}{l}\text { Low operative } \\
\text { performance } \\
\text { and bagging } \\
\text { problems during } \\
\text { execution }\end{array}$ & 1.0687 & 2.3716 & 0.6893 & 3 \\
\hline $\begin{array}{l}\text { Total software } \\
\text { blockade }\end{array}$ & 0.7811 & 2.6593 & 0.7729 & 2 \\
\hline
\end{tabular}

Source: Authors

The first-ranked failure in the given ranking is the inability to meet customer demands and dysfunctionality, and it has the biggest impact on software usability. The second-ranked failure in the given ranking is the total software blockade. It is clear that software engineers primarily need to undertake activities for the elimination of these two failures. Some of the activities are implicative of finding oversights in the software development process that lead to the occurrence of these failures. Sometimes, these oversights can be eliminated if they are minor. It is not a rare case that a program must be written from the very beginning, i.e. it must be subjected to the execution of software re-engineering. It is necessary that an updated software version should be tested so as to determine the (no)existence of such failures. The third- and fourth-ranked failures in the giving ranking are the low operative performance and bagging problems during execution failure, and the upgrade inability failure, respectively. According to the obtained relative closeness coefficient values, these failures can be said to have an almost similar impact on software usability, which further means that the activities for the elimination of these failures should simultaneously be carried out. The failure ranked the last is the inadequate graphic user interface design, with a significantly low impact on the software quality.

\section{CONCLUSION}

It is clear that the assessment and determination of the priority of failures, as well as the existence of a number of issues, take an important place. In this paper, a novel approach to the assessment and ranking of failures in the IT sector is presented. Based on the obtained results, the decision-maker may define the appropriate activities that should lead to a decrease in the risk of delivering a product with a failure to the customer, which further propagates long term sustainability. The proposed model was tested against real-life data.

- The key results of this research study are as follows:

- The new tables (related to severity and detection) for the IT sector are created.

- The new cost severity index is generated. 
- The relative importance of the defined severity, occurrence and detection is determined by applying the BWM method.

- All the changes, inclusive of the changes in the number of failures, can easily be incorporated into the model.

The considered problem may be described by using the formal language as an MCDM problem enabling the determination of the failure rank in an exact manner, for which reason the first hypothesis has been proven.

Activity undertaking in the shown order may bring about a reduction in the time spent and the cost incurred in the software updating process. In this manner, the second hypothesis has been proven.

Beside the aforementioned various advantages of the proposed model for the selection of failures, there are certain limitations pertaining to it, namely:

- The new approach is complex and timeconsuming, just like the other models combining the MDCM and the FMEA methods. Therefore, a certain automatized solution is needed in order to overcome this problem.

- The rating of the relative importance of severity, occurrence and detection, as well as their values, depends on decision-makers' knowledge and experiences.

- Although, sometimes, the effect of a failure does not lead to a safety consequence, this factor is still taken into consideration in the course of risk evaluation.

At the same time, the proposed model can be applied to the assessment and ranking of failures in IT companies operating in a real environment.

A further research study should include new aspects in the severity index.

\section{ACKNOWLEDGEMENTS}

This paper was supported by the Croatian Science Foundation under the project entitled "Innovative Smart Enterprise - INSENT" (1353) and by the European Commission under the "Green-Tech-WB: Smart and Green Technologies for Innovative and Sustainable Societies in Western Balkans" Erasmus Mundus Project (551984-EM-1-2014-1-ES-ERA MUNDUS-EMA2).

\section{REFERENCES}

Abdelgawad, M., \& Fayek, A. R. (2010). Risk management in the construction industry using combined fuzzy FMEA and fuzzy AHP. Journal of Construction Engineering and Management, 136(9), 1028-1036. doi.org/10.1061/(ASCE) C0.1943-7862.0000210

Aslani, R., Feili, H., \& Javanshir, H. (2014). A hybrid of fuzzy FMEA-AHP to determine factors affecting alternator failure causes. Management Science Letters, 4(9), 1981-1984. doi:10.5267/j.msl.2014.8.024

Banduka, N., Tadić, D., Mačužić, I., Crnjac, M. (2018). Extened Process Failure Mode and Effect Analysis (PFMEA) for automotive industry: The FSQC-PFMEA, acceptged for publishing for tom Advances in Production Engineering $\mathcal{E}$ Management.

Belohlavek, R., \& Klir, G. J. (2011). Concepts and Fuzzy Logic. MIT Press.

Carmignani, G. (2009). An integrated structural framework to cost-based FMECA: The priority-cost FMECA. Reliability Engineering \& System Safety, 94(4), 861-871.

Chang, D. Y. (1996). Applications of the extent analysis method on fuzzy AHP. European journal of operational research, 95(3), 649-655.

Dedrick, J., Kraemer, K. L., \& Shih, E. (2013). Information technology and productivity in developed and developing countries. Journal of Management Information Systems, 30(1), 97-122.

Gabus, A., \& Fontela, E. (1972). World Problems, an Invitation to Further Thought Within the Framework of DEMATEL. Geneva, Switzerland: Battelle Geneva Research Center. 
Guimarães, A. C. F., Lapa, C. M. F., \& de Lourdes Moreira, M. (2011). Fuzzy methodology applied to probabilistic safety assessment for digital system in nuclear power plants. Nuclear Engineering and Design, 241(9), 3967-3976.

Hwang, C. L., \& Yoon, K. (1981). Methods for multiple attribute decision making. In Multiple attribute decision making (pp. 58191). Springer, Berlin, Heidelberg.

Kutlu, A. C., \& Ekmekçioğlu, M. (2012). Fuzzy failure modes and effects analysis by using fuzzy TOPSIS-based fuzzy AHP. Expert Systems with Applications, 39(1), 61-67.

Liu, H. C., Qin, J. T., Mao, L. X., \& Zhang, Z. Y. (2015). Personnel Selection Using Interval 2-Tuple Linguistic VIKOR Method. Human Factors and Ergonomics in Manufacturing \& Service Industries, 25(3), 370-384.

Liu, H. C., You, J. X., Li, P., \& Su, Q. (2016). Failure mode and effect analysis under uncertainty: An integrated multiple criteria decision making approach. IEEE Transactions on Reliability, 65(3), 1380-1392.

Opricovic, S., \& Tzeng, G. H. (2004). Compromise solution by MCDM methods: A comparative analysis of VIKOR and TOPSIS. European journal of operational research, 156(2), 445455.
Papaioannou, S. K., \& Dimelis, S. P. (2007). Information technology as a factor of economic development: Evidence from developed and developing countries. Economics of Innovation and New Technology, 16(3), 179-194.

Pawlak, Z. (1982). Rough sets. International journal of computer E information sciences, 11(5), 341-356.

Rezaei, J. (2015). Best-worst multi-criteria decision-making method. Omega, 53, 49-57.

Saaty, T. L. (1990). An exposition of the AHP in reply to the paper "remarks on the analytic hierarchy process". Management science, 36(3), 259-268.

Signor, M. C. (2002). The failure-analysis matrix: A Kinder, gentler alternative to FMEA for information systems. In Reliability and Maintainability Symposium, 2002. Proceedings. Annual (pp. 173-177). IEEE.

Silva, M. M., de Gusmão, A. P. H., Poleto, T., e Silva, L. C., \& Costa, A. P. C. S. (2014). A multidimensional approach to information security risk management using FMEA and fuzzy theory. International Journal of Information Management, 34(6), 733-740. 
Marin Peko is a Ph.D. student at the Faculty of Electrical Engineering, Mechanical Engineering and Naval Architecture, University of Split, Split, The Republic of Croatia. His field of research includes computer science and ICT technology.

Nikola Komatina is a research assistant and a first-year Ph.D. student at the Faculty of Engineering, University of Kragujevac, Kragujevac, The Republic of Serbia. His field of research includes operational research and supply-chain management.

Nikola Banduka is a Ph.D. candidate at the Faculty of Engineering, University of Kragujevac, Kragujevac, The Republic of Serbia, and the Faculty of Electrical Engineering, Mechanical Engineering and Naval Architecture, University of Split, Split, The Republic of Croatia. His field of research includes industrial engineering and risk analysis.

Marina Crnjac is a Ph.D. candidate at the Faculty of Electrical Engineering, Mechanical Engineering and Naval Architecture, University of Split, Split, The Republic of Croatia. Her field of research includes industrial engineering. 


\title{
OCENA I RANGIRANJE GREŠAKA U INDUSTRIJI INFORMACIONIH TEHNOLOGIJA ZASNOVANI NA FMEA I VIŠEKRITERIJUMSKOJ OPTIMIZACIJI
}

\author{
Marin Peko', Nikola Komatina², Nikola Banduka,2, i Marina Crnjac ${ }^{2}$ \\ ${ }^{1}$ Fakultet elektrotehnike, strojarstva i brodogradnje, Univerzitet u Splitu \\ ${ }^{2}$ Fakultet inženjerskih nauka Univerziteta u Kragujevcu
}

\begin{abstract}
Globalizacija i savremeni trendovi uslovili su ubrzan razvoj i primenu informacionih tehnologija, koje danas postaju jedna od najznačajnijih grana privrede svake razvijene države. Prema rezultatima iz prakse može se uvideti da primena software-a koji tokom rada prave različite greške, mogu dovesti do ozbiljnih posledica. Analiza i eliminacija potencijalnih grešaka u komercijalnim software-ima predstavlja problem koji se može označiti kao jedan od osnovnih zadataka inženjera. U ovom radu predložen je novi integrisani model za ocenu i rangiranje potencijalnih grešaka kod software-a, zasnovan na Failure Mode and Effects Analysis (FMEA) i višekriterijumskoj optimizaciji. FMEA analiza primenjena je tako da je troškovni aspekt uvršten u standardni indeks ozbiljnosti posledice, a uz to, pri analizi grešaka, razmatrana su i ostala dva indeksa (faktora) FMEA analize, odnosno mogućnost detekcije i učestalost pojave grešaka. Vrednosti težinskih koeficijenata indeksa ozbiljnosti posledice, mogućnosti detekcije i učestalosti pojave grešaka određene su primenom Best-Worst metode. Određivanje ranga razmatranih grešaka izvršeno je pomoću konvencionalne metode Technique for Order of Preference by Similarity to Ideal Solution (TOPSIS). U skladu sa dobijenim rangom, određen je prioritet aktivnosti koje se preduzimaju kako bi se eliminisale identifikovane greške. Predloženi model testiran je na podacima iz prakse.
\end{abstract}

Ključne reči: razvoj software-a, Failure Mode and Effects Analysis, Best-Worst, Technique for Order of Preference by Similarity to Ideal Solution

JEL Classification: C6, I2 